Provided for non-commercial research and education use. Not for reproduction, distribution or commercial use.

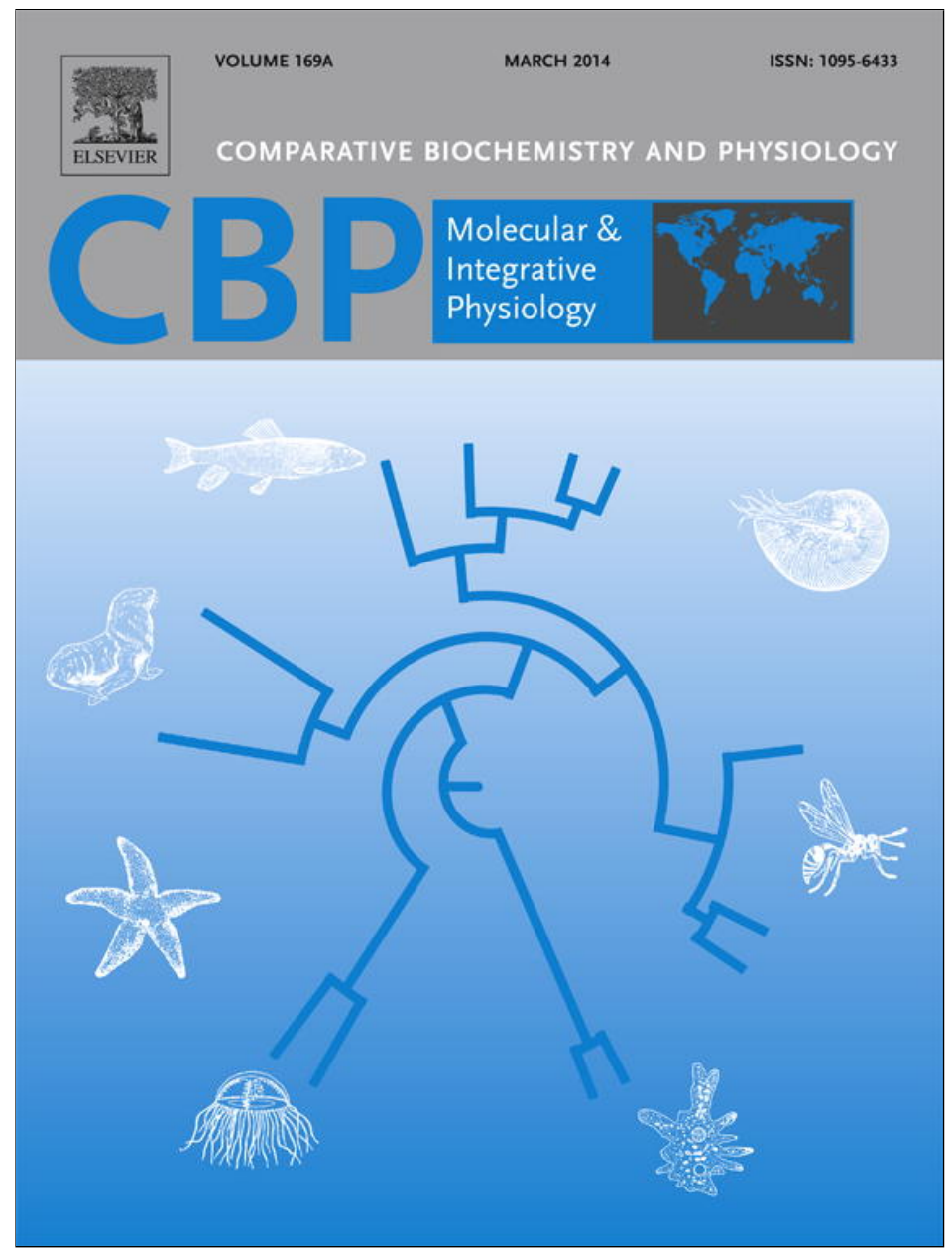

This article appeared in a journal published by Elsevier. The attached copy is furnished to the author for internal non-commercial research and education use, including for instruction at the authors institution and sharing with colleagues.

Other uses, including reproduction and distribution, or selling or licensing copies, or posting to personal, institutional or third party websites are prohibited.

In most cases authors are permitted to post their version of the article (e.g. in Word or Tex form) to their personal website or institutional repository. Authors requiring further information regarding Elsevier's archiving and manuscript policies are encouraged to visit:

http://www.elsevier.com/authorsrights 


\title{
Smelling salt: Calcium as an odourant for fathead minnows
}

\author{
William A. Dew ${ }^{\mathrm{b}}$, Greg G. Pyle ${ }^{\mathrm{a}, \mathrm{b}, *}$ \\ a Department of Biology, Lakehead University, Thunder Bay, Ontario, P7B $5 E 1$ Canada \\ ${ }^{\mathrm{b}}$ Biological Sciences, University of Lethbridge, Lethbridge, Alberta, T1K $3 \mathrm{M} 4$ Canada
}

\section{A R T I C L E I N F O}

\section{Article history:}

Received 4 October 2013

Received in revised form 5 December 2013

Accepted 6 December 2013

Available online 12 December 2013

\section{Keywords:}

Calcium

Olfaction

Electro-olfactography

Behaviour

Cross-adaptation

\begin{abstract}
A B S T R A C T
Calcium plays an essential role in olfactory sensory neuron function. Studies with fish have indicated that in addition to being involved in olfactory signalling, calcium is itself an odourant. In this study we used fathead minnows (Pimephales promelas) and employed two different techniques; electro-olfactography (EOG), a neurophysiological technique that measures olfactory acuity at the olfactory epithelium, and a behavioural choice assay using a trough maze. The results demonstrate that calcium and a known odourant L-arginine are cross-adaptive, that calcium induces an EOG response in a concentration-dependent manner, and that calcium induces a strong avoidance behaviour. The behavioural avoidance was also demonstrated to be olfactorydependent. Taken together, the results demonstrate that calcium is a potent odourant for fathead minnows. Being able to smell calcium may represent an ability to sense and avoid areas with significant changes in ionic strength, thereby avoiding physiological stress.
\end{abstract}

(c) 2013 Elsevier Inc. All rights reserved.

\section{Introduction}

Calcium ions play a vital role in the basic function of olfactory sensory neurons (OSNs), by being involved in the formation of an electrochemical gradient across the cell membrane and in olfactory signalling (Schild and Restrepo, 1998; Firestein, 2001). Evidence shows that in addition to being a vital element in basic olfaction, calcium is recognized by the olfactory epithelium (OE) of fish as an odourant (Bodznick, 1978; Hubbard et al., 2000). Response of fish to calcium as an odourant was first demonstrated by Bodznick (1978), where sockeye salmon (Oncorhynchus nerka Walbaum 1792) fry produced an electroencephalogram (EEG) response at the olfactory bulb to calcium and preferred natural waters than natural waters with added calcium. Subsequent work measuring EEG or olfactory nerve responses in other fish species demonstrated that estuarine and saltwater teleost species respond to decreasing calcium concentrations (Hubbard et al., 2000; Velez et al., 2009), whereas freshwater species respond to increasing calcium concentrations (Bodznick, 1978; Hubbard et al., 2002).

In addition to behavioural and EEG responses to calcium, molecular studies have demonstrated that gene transcripts for calcium receptors are expressed in Atlantic salmon (Salmo salar Linnaeus 1758) (Dukes et al., 2006). Immunocytochemistry has also been used to detect the presence of a $\mathrm{Ca}^{2+}$-sensing receptor (CaR) in goldfish (Hubbard et al.,

Abbreviations: $\mathrm{CaR}, \mathrm{Ca}^{2+}$-sensing receptor; EEG, electro-encephalogram; EOG, electro-olfactography; $\mathrm{OE}$, olfactory epithelium; OSN, olfactory sensory neurons.

* Corresponding author at: Biological Sciences, University of Lethbridge, 4401 University Drive, Lethbridge, Alberta, T1K 3M4, Canada. Tel.: +1 403332 4048; fax: +1 4033292082.

E-mail address: gregory.pyle@uleth.ca (G.G. Pyle).
2002) and dogfish shark (Squalus acanthias Linnaeus 1758) (Nearing et al., 2002). A variety of tissues and organs in fish contain $\mathrm{CaR}$, and are involved in pathways that measure and regulate extracellular calcium concentrations (Loretz, 2008). In internal tissues and organs, such as kidneys, this sensing allows for homeostatic control of ions; however, when present in external tissues such as gills and OSNs, their function is not as clear. In OSNs, the CaRs could be acting as odourant receptors, be part of a homeostatic control, or both (Loretz, 2008). Studies have demonstrated, in other tissues, that in addition to calcium, CaR responds to amino acids (Conigrave et al., 2000, 2007a, 2007b). Therefore, if calcium is binding to CaR in the olfactory epithelium and eliciting a response, it is likely that L-arginine is also binding to $\mathrm{CaR}$ and this is the source of the cross-adaptation. Even though there are calcium sensing receptors present in OSNs, it does not mean that these receptors are acting as traditional olfactory receptors.

Recently, we demonstrated that fathead minnows (Pimephales promelas Rafinesque 1820) exposed to calcium for 3 or $96 \mathrm{~h}$ had a smaller olfactory response to L-arginine than untreated controls (Dew et al., 2012). We hypothesized that this decrease in response may be due to cross-adaptation between calcium and L-arginine. Cross-adaptation occurs when two odourants have an overlap in the OSNs that recognize each odourant individually, such that when the $\mathrm{OE}$ is stimulated by one of the odourants, OSNs that would normally respond to the second odourant cannot respond to a second stimulus because they are already activated by the first odourant (Hansen et al., 2003; Michel et al., 2003; Rolen et al., 2003). Cross-adaptation, therefore, results in a reduced olfactory response to a second odourant after a first odourant has already activated OSNs required to perceive the second odourant.

There are a number of gaps within the knowledge about calcium acting as an odourant for fish. It is unknown if a response of the $\mathrm{OE}$ to 
calcium can be measured, and if any such response is comparable to other odourants. In terms of behaviour, the only other report of the response of fish to calcium is a report by Bodznick (1978). In that study, fish were given the choice of natal water or natal water with an increased concentration of calcium from $\mathrm{CaCl}_{2}$. Fish were shown to prefer the water without the added calcium, which led to the conclusion that the fish are attracted to natal waters. It is also possible, however, that the calcium was inducing an avoidance behaviour in the fish. In addition, the behavioural study did not consider that the counter anion could be inducing the behavioural response, nor did it demonstrate that the response was dependent on olfaction.

In order to further investigate the various gaps outlined above, we employed electro-olfactography (EOG), a technique that measures changes in the extracellular field potential at the $\mathrm{OE}$ due to the addition of an odourant (Scott and Scott-Johnson, 2002) and a behavioural assay. These two techniques were used to investigate various aspects of the response of fathead minnows to calcium. Cross-adaptation between Larginine and calcium was investigated to determine if calcium was blocking the response to L-arginine and vice versa to explain the data in Dew et al. (2012). In addition, EOG was employed to determine if the response to calcium was concentration dependent. For behavioural experiments, tests were done to determine if there was a similar avoidance to calcium in fathead minnows as was shown in sockeye salmon, if this response was concentration dependent, if the response was due to calcium and not an effect of a counter anion, and if the response to calcium did, in fact, require the olfactory system. This work fills in a number of outstanding gaps in our understanding of how calcium acts as an odourant for fish.

\section{Materials and methods}

\subsection{Animals}

Adult fathead minnows (1-4 g; Pimephales promelas Rafinesque 1820; Cypriniformes, Cyprinidae) were obtained from the USEPA (Duluth, MN, USA) and held at the Lakehead University Biology Aquatic Facility in a static renewal system at a density not exceeding one fish per litre. A 16 h light: 8 h dark photoperiod was maintained and all fish were held in dechlorinated Thunder Bay, Ontario (Canada) municipal water (Table 1). All fish were fed ad libitum once a day, with Artemia spp. and commercial fish flakes (Tetra, Blacksburg, VA, USA) on alternate days. All fish were allowed to acclimate to laboratory conditions for a minimum of two weeks before being used in experiments. All experiments were performed in accordance with the Canadian Council on Animal Care guidelines.

\subsection{Electro-olfactography experiments}

Electro-olfactography experiments were performed as previously described (Green et al., 2010). Fish were anaesthetized in $120 \mathrm{mgL}^{-1}$ of pH 7.4 buffered MS-222 (Syndel Laboratories Inc, Qualicum Beach, BC, Canada). Each olfactory stimulus was administered to the olfactory chamber a minimum of 3 times, with the order of stimulus delivery randomized for each fish to avoid any systematic bias to recorded

Table 1

Basic water quality measurements of dechlorinated Thunder Bay Municipal water. All values are mean \pm s.e.m., except for $\mathrm{pH}$ and temperature which are presented a ranges $(n=3)$

\begin{tabular}{ll}
\hline Water quality variable & Measured value \\
\hline Calcium & $13.9 \pm 0.35 \mathrm{mgL}^{-1}$ \\
Magnesium & $2.8 \pm 0.04 \mathrm{mgL}^{-1}$ \\
Sodium & $3.4 \pm 0.01 \mathrm{mgL}^{-1}$ \\
Temperature & $19.5-20.5{ }^{\circ} \mathrm{C}$ \\
pH & $7.29-7.79$ \\
Alkalinity & $50.4 \pm 1.8 \mathrm{mgL}^{-1}$ as CaCO $_{3}$ \\
\hline
\end{tabular}

responses as a function of delivery order. There was a delay of at least two minutes between each stimulus delivery to ensure the OE had sufficient time to recover from the previous stimulus delivery. The amplitude of each EOG response was measured by determining the difference between the baseline and the maximum response after a stimulus delivery. All measured EOG responses to each stimulus were blank corrected by subtracting any response elicited to a blank stimulus. The composition of the blank stimulus depended on which experimental procedure was used, as detailed below.

\subsection{Cross-adaptation methodology}

Olfactory cross-adaptation between L-arginine and calcium was tested by first measuring the EOG response of an animal to either $1 \mathrm{mM}$ L-arginine (Sigma, Oakville, ON, Canada) or $1 \mathrm{mM}$ calcium (as $\mathrm{Ca}\left(\mathrm{NO}_{3}\right)_{2}$; Sigma). Animals were then adapted to either calcium (if response to L-arginine was initially measured) or L-arginine (if response to calcium was initially measured) alone for a minimum of $10 \mathrm{~min}$. Adaptation was accomplished by irrigating the olfactory rosettes with water containing either $1 \mathrm{mM}$ of L-arginine or $1 \mathrm{mM}$ of calcium, as appropriate. After the $10 \mathrm{~min}$ adaptation period, the L-arginine-adapted animals were tested for their olfactory response (using EOG) to $1 \mathrm{mM}$ calcium and the calcium-adapted animals were tested for their olfactory response to $1 \mathrm{mM}$ L-arginine. The initial and post-adaption response to each cue was corrected using an appropriate blank consisting of the irrigation water. The percent unadapted response for each animal was calculated by dividing the post-adaption response by the initial response for each cue. Any reduction in EOG response during the coexposure would positively indicate for cross-adaptation.

\subsection{Calcium concentration curve}

To test if calcium induces a concentration dependent EOG response in fathead minnows, four different nominal concentrations of calcium $(0.1,1,10$, and $100 \mathrm{mM}$ nominal concentrations) were made from stock solutions of $\mathrm{Ca}\left(\mathrm{NO}_{3}\right)_{2}$ in dechlorinated water, which itself contained approximately $0.35 \mathrm{mM}$ calcium. Each nominal concentration, therefore, represents the concentration of added and not total calcium. Calcium concentrations were measured using inductively coupled plasma atomic emission spectroscopy (ICP-AES) by the Lakehead University Centre for Analytical Services (LUCAS). The LUCAS laboratory is accredited through the Canadian Association for Laboratory Accreditation (CALA). The concentration of calcium in the dechlorinated water was subtracted from the water to determine the added calcium concentration. Measured concentrations of calcium were $92-106 \%$ of nominal concentrations (Table 2 ). The EOG response to each of the four calcium solutions as well as a blank containing no added calcium was measured. Each response was blank corrected and averaged for each concentration.

\section{Table 2}

Comparison of measured and nominal calcium concentrations. All values are mean \pm s.e.m. The first four concentrations represent calcium solutions made using $\mathrm{Ca}\left(\mathrm{NO}_{3}\right)_{2}$, the fifth concentration represents a solution made using $\mathrm{CaCl}_{2}$. All concentrations were corrected for the concentration of calcium in the background dechlorinated water, and as such represent added calcium, not total calcium.

\begin{tabular}{lc}
\hline Nominal concentration $(\mathrm{mM})$ & Measured value $(\mathrm{mM})$ \\
\hline 0.1 & $0.1 \pm 0.00$ \\
1.0 & $1.1 \pm 0.00$ \\
10 & $10.2 \pm 0.01$ \\
100 & $96.6 \pm 0.26$ \\
$10\left(\mathrm{CaCl}_{2}\right)$ & $9.1 \pm 0.03$ \\
\hline
\end{tabular}




\subsection{Behavioural assay method}

For all behavioural choice assays, opaque trough mazes were used. Each trough measured $69 \mathrm{~cm} \times 14 \mathrm{~cm} \times 16 \mathrm{~cm}(\mathrm{~L} \times \mathrm{W} \times \mathrm{H})$. The bottom of each trough was covered in white corrugated plastic (Coroplast, Granby, Québec, Canada), which was sealed to the sides and bottom of the maze using aquarium grade sealant. Lines were drawn on the corrugated plastic, splitting the bottom into three separate areas. A plexiglass diffusion chamber was placed into both ends of the trough maze. These diffusion chambers measured $7.5 \mathrm{~cm} \times 13 \mathrm{~cm} \times 15.5 \mathrm{~cm}$ $(\mathrm{L} \times \mathrm{W} \times \mathrm{H})$, and had 32-0.5 cm diameter holes drilled through each side of the chamber $1 \mathrm{~cm}$ from the bottom, which allowed for even stimulus release into the maze environment. The trough was filled with $10 \mathrm{~L}$ of dechlorinated water at $19-20^{\circ} \mathrm{C}$. A bottomless translucent plastic box (the acclimation chamber) measuring $19 \mathrm{~cm} \times 13 \mathrm{~cm} \times 11 \mathrm{~cm}$ $(\mathrm{L} \times \mathrm{W} \times \mathrm{H})$ was placed into the middle section on the bottom of the maze (the acclimation zone). This plastic box was attached to a string that could be pulled from behind a blind to allow for the box to be raised without the fish being able to see the observer. At the beginning of each trial a fathead minnow was placed into the acclimation chamber, $50 \mathrm{~mL}$ of the stimulus for the trial was added to one of the diffusion chambers and $50 \mathrm{~mL}$ of dechlorinated water (blank) was added to the diffusion chamber on the opposite end. The stimulus was allowed to diffuse for $20 \mathrm{~min}$, which also allowed the fish to acclimate to maze conditions. After this 20 min period, the acclimation chamber was lifted off the bottom to just below the surface of the water to ensure that the surface of the water was not disturbed. Each fish was monitored using a web camera (RocketFish, Richfield, MN, USA) attached to a MacBook computer. The position of the fish in the maze, either the stimulus arm, blank arm, or acclimation zone, was recorded every $10 \mathrm{~s}$ for a total of $8 \mathrm{~min}$. The number of times each fish was in each location was tallied and multiplied by 10 to derive time spent in each arm.

\subsection{Behavioural response to calcium}

To measure the response of fathead minnows to calcium, the behavioural assay method detailed above was used with the four different concentrations of calcium that were used in the calcium concentration curve EOG experiment (Table 2). To eliminate the possibility that the behavioural response to calcium was due to the counter ion of the calcium salt being used, $\mathrm{Ca}\left(\mathrm{NO}_{3}\right)_{2}$, a second calcium salt, $\mathrm{CaCl}_{2}$ (Sigma), was used to make a nominal $10 \mathrm{mM}$ added calcium solution ( $9.1 \mathrm{mM}$ measured, Table 2). This calcium solution was then used as the stimulus in a subsequent behavioural experiment.

It is possible that the behavioural response to calcium was mediated by some other tissue or sense besides olfaction. To determine if the behavioural response was olfactory-mediated, behavioural trials were performed with anosmic fish. Fathead minnows were made anosmic by the application of Vetbond tissue adhesive ( $3 \mathrm{M}$, St. Paul, MN, USA) to their olfactory chambers. Fish were first lightly anaesthetised in water containing $120 \mathrm{mgL}^{-1} \mathrm{MS}-222$ buffered to $\mathrm{pH}$ 7.5. The snout of each fish was dried and excess water was removed from each naris using a folded KimWipe (Kimberly-Clark, Dallas, TX, USA). Using a pipette tip, 2-3 $\mu \mathrm{L}$ of Vetbond was added to each naris. The Vetbond was allowed to dry (5-10 s) and the fish was placed into a tank of aerated water to recover. For a control, a second group of fish were treated in exactly the same manner, except $2-3 \mu \mathrm{L}$ of dechlorinated water was added to each olfactory chamber instead of the Vetbond adhesive. Fish were allowed to recover overnight, after which their response to $10 \mathrm{mM}$ calcium (using $\mathrm{Ca}\left(\mathrm{NO}_{2}\right)_{3}$ as the calcium salt) was measured.

\subsection{Statistical analysis}

All statistical analyses were conducting using R, version 2.13.0 ( $R$ Development Core Team, 2012). All graphics were made using the sciplot package (Morales, 2012). For the cross-adaptation study, the percent unadapted response of each cue was analysed using a onesample $t$-test against $100 \%$, with a Benjamini-Hochberg $p$-value correction to compensate for multiple comparisons. As the calcium concentration curve experiment represented multiple measurements on the same fish, a repeated measures analysis of variance was used to detect significant differences among groups, followed by a Tukey's test to determine differences among individual groups. For behavioural trials, outliers were detected using a Grubbs test followed by a paired $t$-test (when data were parametric) or paired Wilcox test (when data were nonparametric) to determine if there was a difference between time spent in the stimulus and blank treatment arms. In all cases significance was declared when $p \leq 0.05$.

\section{Results}

\subsection{Cross adaptation of calcium and L-arginine}

When calcium was irrigated across the $\mathrm{OE}$ and L-arginine was used as a cue, there was a significant reduction in EOG $\left(t_{2}=-9.582\right.$, $p<0.03$; Fig. 1). There was an approximately $40 \%$ lower EOG response after calcium was added than before. When L-arginine was irrigated across the $\mathrm{OE}$ and calcium was used as a cue, there was a significant decrease of approximately $40 \%$ in the EOG response to calcium $\left(t_{2}=\right.$ $-5.818, p<0.03$; Fig. 1 ).

\subsection{Concentration curve for calcium}

In order to determine if calcium induces a concentration-dependent EOG response, four different concentrations of calcium $(0.1,1.0,10$, and $100 \mathrm{mM}$ ) were used as stimuli. The results demonstrate that there is, in fact, a concentration-dependent EOG response to increasing concentrations of calcium $\left(F_{3,11}=4.287, p<0.01\right.$; Fig. $\left.2 \mathrm{~A}\right)$. The greater the concentration of calcium used as an odour, the greater the EOG response.

The response induced by each of the four concentrations of calcium was extracted and compared, as shown in Fig. 2B. The EOG response increases as concentration of calcium increases, however, it is important to note that at the two highest concentrations of calcium used there was a small to moderate positive waveform in the trace immediately before the depolarization. This initial positive waveform appeared to delay the depolarization as compared to the two lower concentrations of calcium.

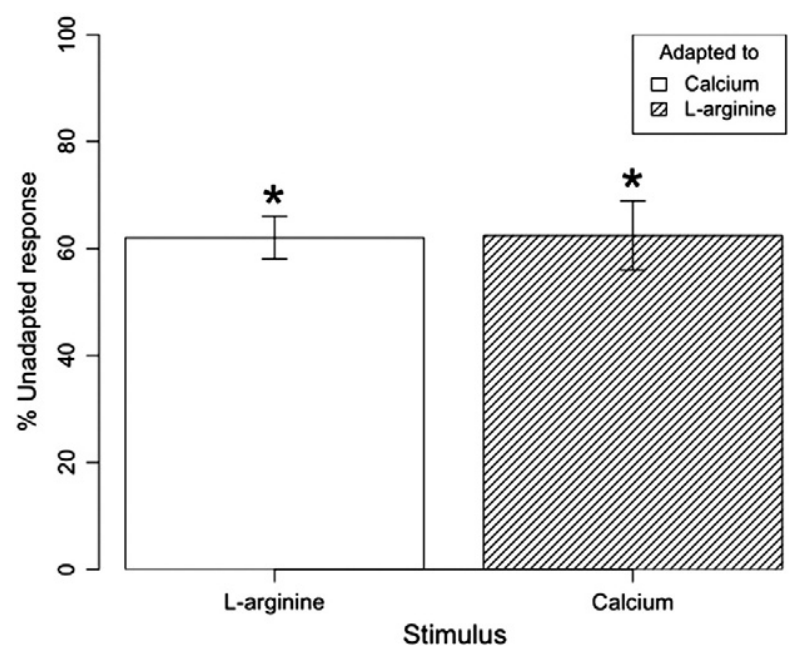

Fig. 1. The percent unadapted response ( \pm s.e.m.) of L-arginine when calcium is used as the adapting agent, and vice versa. An asterisk denotes significant difference from $100 \%$ using a one-sample $t$-test when $p \leq 0.05$ ( $n=3$ per bar). 
A

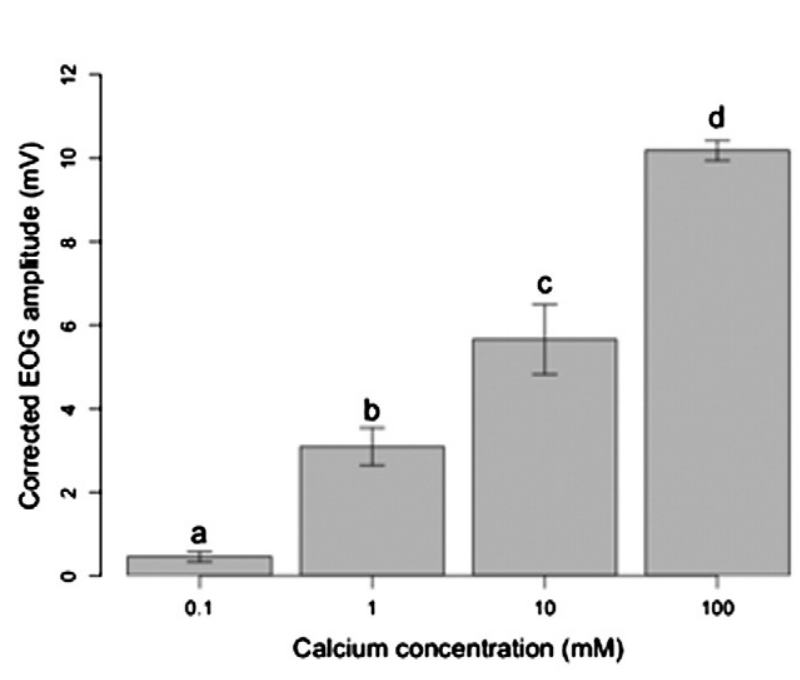

B

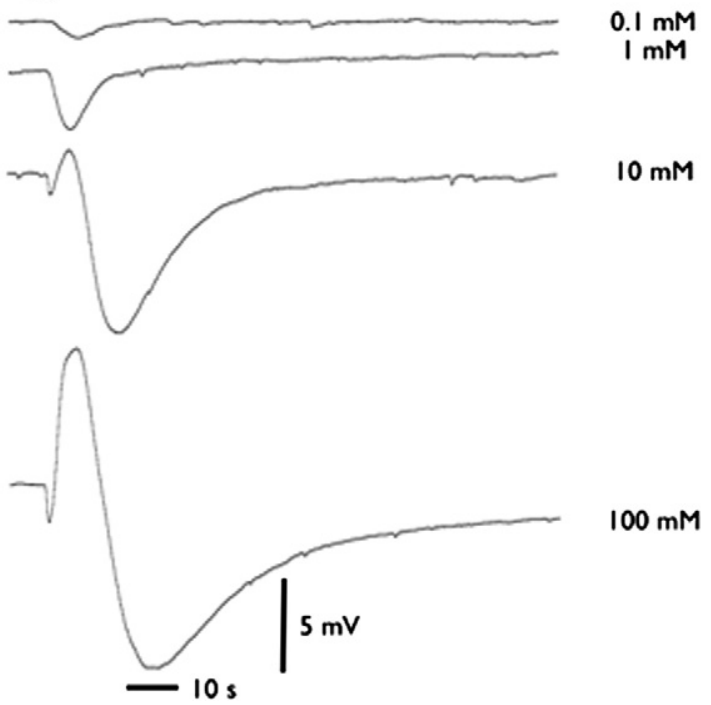

Fig. 2. Concentration-dependent EOG response ( \pm s.e.m.) of fathead minnows to calcium. Bars with different letters are significantly different from each other when $p \leq 0.05$ ( $n=3-5$ per bar).

\subsection{EOG trace comparison}

Examples of the raw trace of the response of the $\mathrm{OE}$ to $1 \mathrm{mM}$ calcium and $1 \mathrm{mM}$ L-arginine were compared (Fig. 3). For both odourants, the initiation of the EOG response occurred at the same time after the addition of the odourant. The calcium-induced EOG response recovered to baseline faster than the L-arginine-induced EOG response.

\subsection{Behavioural response to calcium}

At the three highest concentrations of calcium tested, fathead minnows spent significantly more time in the arm containing the blank than the arm containing the added calcium. This avoidance of calcium was seen when $100 \mathrm{mM}(V=104, p<0.01), 10 \mathrm{mM}(V=104$, $p<0.01)$, or $1 \mathrm{mM}(V=87, p<0.04)$ calcium was used (Fig. 4$)$. However, there was no significant difference between time spent in the arm containing the blank or $0.1 \mathrm{mM}$ calcium $(V=59, p=0.71$; Fig. 4$)$.

To ensure that the behavioural response was to calcium and not the counter ion of the calcium salt used, the behavioural response to a second calcium salt, calcium chloride $\left(\mathrm{CaCl}_{2}\right)$, was measured. When $10 \mathrm{mM}$ calcium chloride was used as the stimulus, fathead minnows spent more time in the arm given a blank than the stimulus $(V=63$, $p<0.01$; Fig. 5). This response was in line with the response seen when calcium nitrate was used.

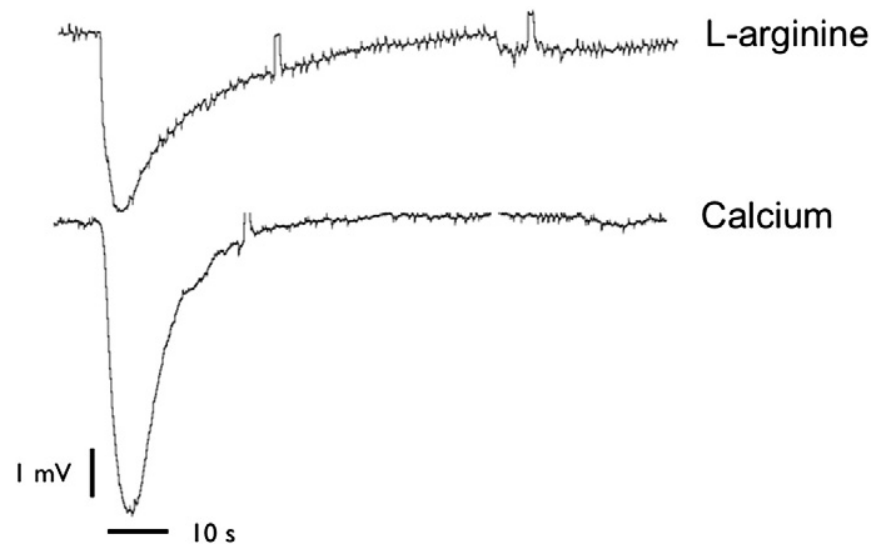

Fig. 3. EOG traces for $1 \mathrm{mM}$ L-arginine and $1 \mathrm{mM}$ calcium.
In order to demonstrate that the behavioural response of fathead minnows to calcium was mediated by olfaction and not another sense, fish were made anosmic using tissue glue. When the behavioural response of fathead minnows to $10 \mathrm{mM}$ calcium was measured, anosmic fish did not show a preference for either end of the maze $\left(t_{12}=0.347\right.$, $p=0.73$; Fig. 6A). However, when fish were given a mock anosmic treatment, they actively avoided the arm that received the calcium cue, similar to what was seen in previous trials $(V=98, p<0.01$; Fig. 6B).

\section{Discussion}

This study used both neurophysiological and behavioural assays to answer a variety of questions about calcium sensing in fish. The neurophysiological evidence (via EOG measurements) demonstrated that the $\mathrm{OE}$ of fathead minnows respond to calcium in a dose-dependent manner, as would be expected of an odourant. Other studies have demonstrated that calcium induces a dose-dependent response using a different neurophysiological endpoint (EEG responses at the olfactory bulb) to calcium in sockeye salmon (Bodznick, 1978). Multi-unit extracellular recordings from the olfactory nerve of an estuarine species, gilthead seabream (Sparus aurata Linnaeus 1758), showed that this species was sensitive to changes in calcium concentrations that it is likely to encounter in its natural habitat (Hubbard et al., 2000). Furthermore, goldfish (Carassius auratus Linnaeus 1758) EEG responses to calcium were shown to be concentration-dependent (Hubbard et al., 2002). Interestingly, the cumulative evidence demonstrates that estuarine and salt water species of fish demonstrate a response when presented with a cue containing less calcium than what they are acclimated to, while the addition of increased calcium induces a response in freshwater fish. The current study demonstrates that fathead minnows, a freshwater species, reacts to increasing calcium with an increase in a neurophysiological response, which supports the previous work with freshwater fish. In addition, this is the first study to demonstrate an EOG response to calcium in a fish species. While an EOG response cannot be equated with a fish smelling an odour (i.e., a signal sent to the brain from the OE through the olfactory nerve), it can be used to demonstrate if an odour can be perceived by a fish at the $\mathrm{OE}$. In order to demonstrate that this response at the $\mathrm{OE}$ translates into perception of the cue by the fish, EOG needs to be paired with measurements of higher order biological organization, such as behaviour. 

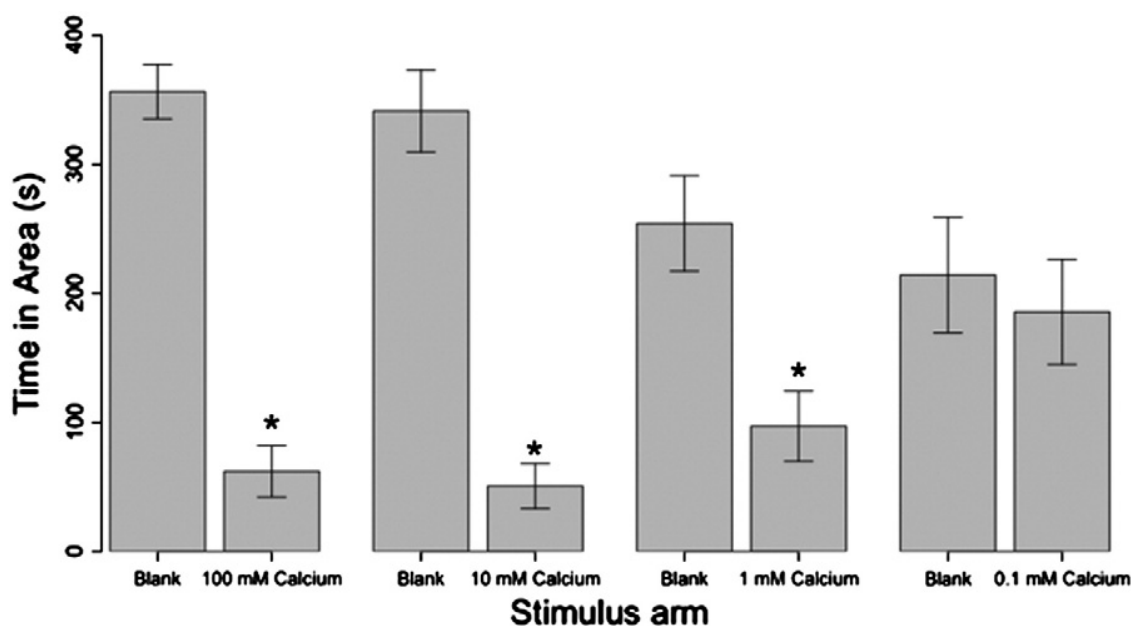

Fig. 4. Avoidance response ( \pm s.e.m.) of fathead minnows to calcium when various concentrations of calcium were used. An asterisk denotes significant difference from the corresponding blank stimulus arm when $p \leq 0.05$ ( $n=14$ per bar).

The current study is the first to demonstrate cross-adaptation between calcium and a second odourant. Cross-adaption has been seen in fish for other stimuli such as polyamines, bile salts and amino acids, but not calcium (Hansen et al., 2003; Michel et al., 2003; Rolen et al., 2003). A study by Hubbard et al. (2002) showed that removal of calcium from the surrounding water for goldfish resulted in a small, but significant, increase in response to L-serine. The authors argued that their results were likely due to a hyperexcitability of fish OSNs, however, it is also possible that their observations were consistent with crossadaptation between calcium and L-serine. Additionally, an investigation into whether or not calcium was cross-adaptive with sodium demonstrated that there was, in fact, no cross-adaptation between the two ions (Hubbard and Canario, 2007). The addition of calcium to the OE of sockeye salmon did not affect the EEG response to L-alanine, most likely because calcium and L-alanine are not cross-adaptive (Bodznick, 1978). Studies have demonstrated that the CaR is present in OSNs, and it is possible that these receptors are what mediate the response to calcium (Hubbard et al., 2002). As amino acids are also recognized by CaR, it is likely that CaR is the source of cross-adaptation between calcium and L-arginine, as both odours would be recognized by CaR (Conigrave et al., 2000, 2007a, 2007b). Regardless of how calcium is being perceived by the olfactory system, be it through receptorbinding (possibly CaR) as is seen with other odourants, direct activation

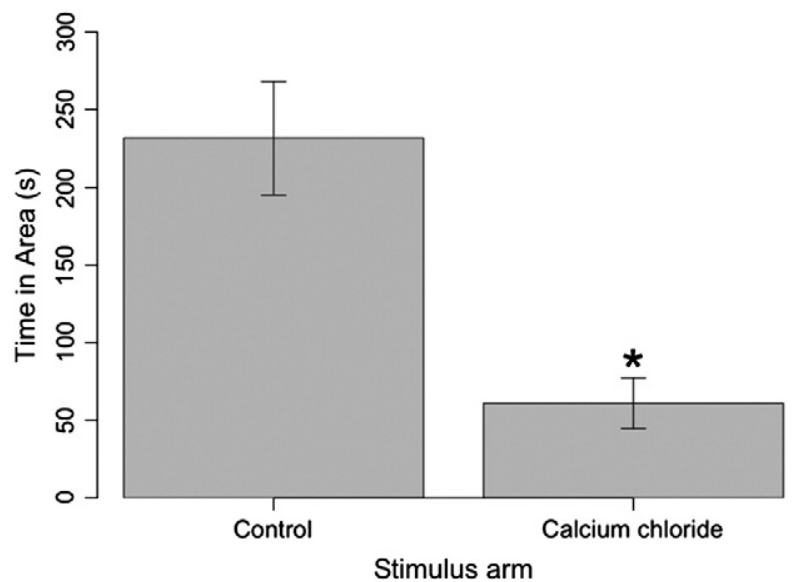

Fig. 5. Avoidance response ( \pm s.e.m.) to calcium chloride. An asterisk denotes significant difference from the control stimulus arm when $p \leq 0.05$ ( $n=12$ per bar). of channel proteins, or some other mechanism, L-arginine interferes with the response of the $\mathrm{OE}$ to calcium. The response of the $\mathrm{OE}$ to Larginine is likewise impaired by the addition of calcium.

It can be argued that any response of the $\mathrm{OE}$ to calcium as measured by EOG is not, in fact, a measure of the reaction of the OE to calcium, but merely due to a change in the conductivity of the water bathing the $\mathrm{OE}$. What looked like an EOG response would in fact be a temporary shift in the baseline that shifts back after the calcium has washed from the OE. However, when the $\mathrm{OE}$ is nonreactive or when it is removed altogether, the addition of calcium induces a waveform in the opposite direction of an EOG (unpublished observations). This positive waveform is most likely because an EOG measures extracellular field potential, and the addition of calcium increased the positive charge present in the extracellular environment bathing the $\mathrm{OE}$. This positive waveform was seen in the EOG trace for the two highest concentrations of calcium (as shown in Fig. 2B), in that both had a positive waveform immediately prior to the expected negative waveform. The positive aspect of the trace was most likely excess calcium that did not bind to odourant receptors. A depolarization was subsequently measured, either due to excess calcium washing off the $\mathrm{OE}$, or the inward current became greater than the effect of calcium and its associated positive charges in the extracellular

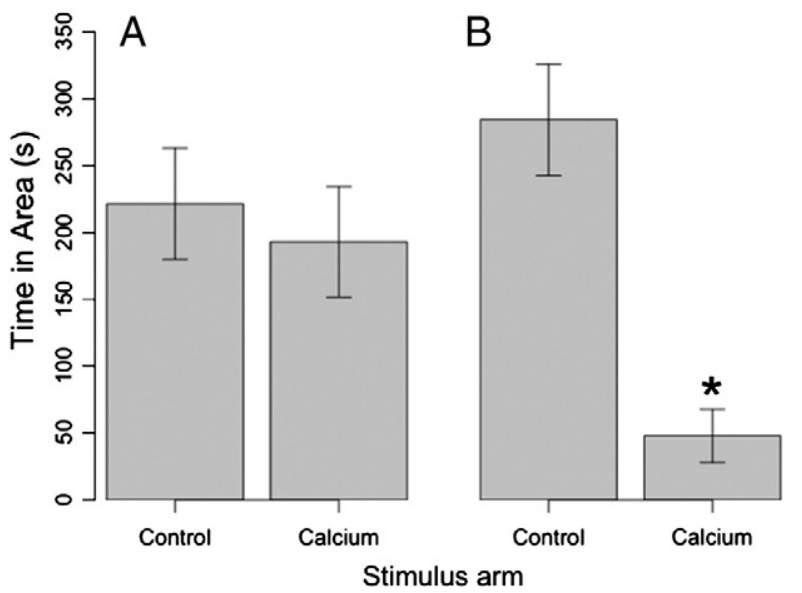

Fig. 6. Behavioural response to calcium of anomsic (A) or intact olfaction (B) fathead minnows to calcium. An asterisk denotes significant difference from the control stimulus arm when $p \leq 0.05$ ( $n=13-14$ per bar). 
environment. Therefore, calcium has an effect on the conductivity of the water bathing the OE, however, it cannot be mistaken for an EOG response as the effect of calcium is to produce a positive waveform. In addition, a comparison of the EOG response for calcium and L-arginine demonstrates that calcium has a similar waveform to another, more well-defined odourant. While the amplitude of the EOG responses to L-arginine and calcium was not identical, the timing of the initiation of the EOG and the time to recover the baseline were similar. The comparison of the traces for calcium and L-arginine further supports calcium as an odourant, and that EOG is a valid technique to investigate the response of the $\mathrm{OE}$ to calcium.

The behavioural endpoint tested in this study clearly demonstrates that fathead minnows avoid calcium. This effect was seen with different calcium salts (calcium nitrate and calcium chloride) providing evidence that the response is due to calcium and not the counter ion of the calcium salt used. Anosmic fish did not react to the presence of calcium, while olfactory-intact fish did. This result demonstrates that the response to calcium is, in fact, mediated by the olfactory system, and not by some other chemosensory modality. A behavioural response to calcium has only been demonstrated once before, and until this study the response had not been demonstrated to be olfactory in nature (Bodznick, 1978). The behavioural study by Bodznick (1978) compared the response of fish to natural waters with and without added calcium. Fish selected the natural waters without the added calcium, and it was interpreted as the fish preferring the natural waters without added calcium. While this is still a valid possibility, in the light of the work presented in the current study, it is more likely that the fish were avoiding the added calcium, not that they were attracted to natural waters without calcium. In addition to calcium, fish have been shown to avoid a number of other cations, including copper, chromium, nickel, cadmium, iron, and zinc (Atchison et al., 1987). Interestingly, a recent paper by Kennedy et al. (2012) demonstrates that at the higher concentrations used $\left(10^{-3}\right.$ and $10^{-4} \mathrm{M}$ ), chinook salmon (Oncorhynchus tshawytscha Walbaum 1792) avoided L-histidine, a positively charged amino acid. The general avoidance of increased concentrations of cations by fish indicates that they may have the ability to not only detect differences in salinity based on calcium and sodium, but may be able to detect cations in general. If there is a general ability of fish to detect positive charges it may explain why calcium and L-arginine are crossadaptive, as both have a positive charge. If calcium binds to calcium receptors in the olfactory epithelium and causes a response, it is possible that L-arginine also binds to these receptors and causes crossadaption. It is also possible that calcium is perceived by the olfactory system through some other mechanism that is perceiving the positively-charged nature of L-arginine. The ability to detect dissolved cations would allow fish to avoid areas that may cause osmotic stress or lead to situations where fish become exposed to potentially toxic metals.

Three hypotheses for why fish detect calcium in water have been proposed. Bodznick (1978) proposed that the ability of sockeye salmon fry to detect calcium was that it helped in the recognition of natal waters. Hubbard et al. (2002) hypothesized that this was a sort of "advance warning system", to let an estuarine fish tell when it had reached the limits of its tolerance (Hubbard et al., 2000). A third hypothesis is that this ability allows a fish to maintain homeostasis of ion content surrounding OSNs (Hubbard et al., 2002). As fathead minnows do not migrate and have no need to recognize changes in salinity, it is most likely that this phenomenon represents a homeostatic control. The ability to sense and respond (through avoidance) to areas that may put a fish into osmotic shock represents a fascinating use of olfaction as an osmoregulatory sense.

\section{Conclusions}

In summary, our study demonstrates that calcium is a potent odourant to fathead minnows at the neurophysiological and behavioural levels. Calcium not only induces a concentration dependent-response at the $\mathrm{OE}$ that can be directly measured, it is cross-adaptive with L-arginine, a well-defined odourant, and causes a strong behavioural avoidance response that is dependent on the olfactory system. The ability to sense and avoid calcium represents a fascinating ability of fish to recognize areas that may prove physiologically detrimental to the fish.

\section{Acknowledgments}

The authors wish to thank Ashely Chadwick for her work in developing the trough maze procedure, and Dr. David Janz for his thoughtful advice. We also thank Dr. Warren Green for his valuable comments on earlier drafts of the manuscript. Frank Whiteman and the USEPA Midcontinent Ecology Division in Duluth, MN provided the fathead minnows. This work was supported by the Natural Sciences and Engineering Research Council of Canada Discovery Grant program. GGP was supported by the Canada Research Chairs program for the duration of this research, and is now supported by a Campus Alberta Innovates Program (CAIP) Research Chair in Aquatic Health.

\section{References}

Atchison, G.J., Henry, M.G., Sandheinrich, M.B., 1987. Effects of metals on fish behavior: a review. Environ. Biol. Fish. 18, 11-25.

Bodznick, D., 1978. Calcium ion: an odorant for natural water discriminations and the migratory behavior of sockeye salmon. J. Comp. Physiol. A. 127, 157-166.

Conigrave, A.D., Quinn, S.J., Brown, E.M., 2000. L-amino acid sensing by the extracellular $\mathrm{Ca}^{2+}$-sensing receptor. Proc. Natl. Acad. Sci. U. S. A. 97, 4814-4819.

Conigrave, A.D., Mun, H.C., Brennan, S.C., 2007a. Physiological significance of L-amino acid sensing by extracellular $\mathrm{Ca}^{2+}$-sensing receptors. Biochem. Soc. Trans. 35, 1195.

Conigrave, D., Mun, H.C., Lok, H.C., 2007b. Aromatic L-amino acids activate the calciumsensing receptor. J. Nutr. 137, 1524S-1527S.

Dew, W.A., Wood, C.M., Pyle, G.G., 2012. Effects of continuous copper exposure and calcium on the olfactory response of fathead minnows. Environ. Sci. Technol. 46, 9019-9026.

Dukes, J.P., Deaville, R., Gottelli, D. Neigel, JE. Bruford, M.W., Jordan, W.C., 2006. Isolation and characterisation of main olfactory and vomeronasal receptor gene families from the Atlantic salmon (Salmo salar). Gene 371, 257-267.

Firestein, S., 2001. How the olfactory system makes sense of scents. Nature 413, 211-218.

Green, W.W., Mirza, R.S., Wood, C.M., Pyle, G.G., 2010. Copper binding dynamics and olfactory impairment in fathead minnows (Pimephales promelas). Environ. Sci. Technol. $44,1431-1437$.

Hansen, A., Rolen, S.H., Anderson, K., Morita, Y., Caprio, J., Finger, T.E., 2003. Correlation between olfactory receptor cell type and function in the channel catfish. J. Neurosci. 23, 9328-9339.

Hubbard, P.C., Canario, A.V., 2007. Evidence that olfactory sensitivities to calcium and sodium are mediated by different mechanisms in the goldfish Carassius auratus. Neurosci. Lett. 414, 90-93.

Hubbard, P.C., Barata, E.N., Canario, A.V., 2000. Olfactory sensitivity to changes in environmental $\left[\mathrm{Ca}^{2+}\right]$ in the marine teleost Sparus aurata. J. Exp. Biol. 203, 3821.

Hubbard, P.C., Ingleton, P.M., Bendell, L.A., Barata, E.N., Canario, A.V.M., 2002. Olfactory sensitivity to changes in environmental $\left[\mathrm{Ca}^{2+}\right]$ in the freshwater teleost Carassius auratus: an olfactory role for the $\mathrm{Ca}(2+)$-sensing receptor? J. Exp. Biol. 205 2755-2764.

Kennedy, C.J., Stecko, P. Truelson, B. Petkovich, D., 2012. Dissolved organic carbon modulates the effects of copper on olfactory-mediated behaviors of chinook salmon. Environ. Toxicol. Chem. 31, 2281-2288.

Loretz, C.A., 2008. Extracellular calcium-sensing receptors in fishes. Comp. Biochem. Physiol. A Mol. Integr. Physiol. 149, 225-245.

Michel, W.C., Sanderson, M.J., Olson, J.K., Lipschitz, D.L., 2003. Evidence of a novel transduction pathway mediating detection of polyamines by the zebrafish olfactory system. J. Exp. Biol. 206, 1697-1706.

Morales, M., 2012. sciplot: Scientific Graphing Functions for Factorial Designs. R package version 1.1-0.

Nearing, J., Betka, M., Quinn, S., Hentschel, H., Elger, M., Baum, M., Bai, M., Chattopadyhay, N., Brown, E.M., Hebert, S.C., 2002. Polyvalent cation receptor proteins (CaRs) are salinity sensors in fish. Proc. Natl. Acad. Sci. 99, 9231-9236.

R Development Core Team, 2012. R: a language and environment for statistical computing. R Foundation for Statistical Computing (version 2.13.1).

Rolen, S.H., Sorensen, P.W., Mattson, D., Caprio, J., 2003. Polyamines as olfactory stimuli in the goldfish Carassius auratus. J. Exp. Biol. 206, 1683.

Schild, D., Restrepo, D., 1998. Transduction mechanisms in vertebrate olfactory receptor cells. Physiol. Rev. 78, 429-466.

Scott, J.W., Scott-Johnson, P.E., 2002. The electroolfactogram: a review of its history and uses. Microsc. Res. Tech. 58, 152-160.

Velez, Z., Hubbard, P.C., Barata, E.N., Canario, A.V., 2009. Adaptation to reduced salinity affects the olfactory sensitivity of Senegalese sole (Solea senegalensis Kaup 1858) to $\mathrm{Ca}^{2+}$ and $\mathrm{Na}^{+}$but not amino acids. J. Exp. Biol. 212, 2532-2540. 